\title{
SURFACE OXIDATION OF AL-SI ALLOYS AT ELEVATED TEMPERATURES
}

\author{
Original scientific paper
}

UDC: 620.193.94:669.71

https://doi.org/10.18485/aeletters.2021.6.3.3

\author{
Adelina Miteva $^{1}$, Anna Petrova $^{1 *}$, Georgi Stefanov ${ }^{2}$ \\ ${ }^{1}$ Space Research and Technology Institute, Bulgarian Academy of Sciences, Bulgaria \\ ${ }^{2}$ Institute of Metal Science, Equipment and Technologies with Hydro- and Aerodynamics "Acad. A. Balevski“, \\ Bulgarian Academy of Sciences, Bulgaria
}

\begin{abstract}
:
Characteristic of the samples based on Al-Si alloys, that we have studied, is their propensity for oxidation at high temperatures. The few number of papers on the oxidation kinetics of aluminium alloys associated with Planar Flow Casting technology (PFC) can be found in the literature. The oxide processes and the properties of the oxide layer formed on the aluminium alloy are mainly considered.

The aim of the present work is the kinetics of oxide layer formation on aluminium alloys to clarify whether alloys are suitable for use in space and under specific conditions. The formal kinetics of Nikitin was applied for data processing. The influence of the alloying elements on the formed surface oxide coating is shown.
\end{abstract}

\section{ARTICLE HISTORY}

Received: 23.04.2021.

Accepted: 24.08.2021.

Available: 30.09.2021.

\section{KEYWORDS}

Al-Si alloys, oxide layer, hot extrusion

\section{INTRODUCTION}

The aluminium alloys have low density and modulus of elasticity, light, susceptible to stamping, high thermal conductivity, corrosion resistance due to passivation through the formation of a dense layer of oxides. When exposed to air, a thin layer forms on the surface, which prevents deep oxidation. High-strength aluminium alloys are more susceptible to corrosion due to the presence of elements such as copper in their composition.

Since parts made of aluminium alloys [1] are used in the space industry [2,3], aviation and automobiles $[4,5]$, it is necessary to study the behavior of aluminium alloys at high temperatures.

The surface oxidation kinetics of a metal or alloy is controlled by a number of processes such as the chemical reaction rate at one or both interfaces (metal/oxide layer or oxide/gas) and by atomic transport through the oxide layer. Aluminium has an affinity for oxygen. The solubility of oxygen in liquid aluminium is very low $(<0.0003 \%)$. The formation of oxides is carried out by the interaction of aluminium and its alloys with oxygen. Aluminium oxide forms several crystal modifications depending on temperature and time.

The speed of diffusion processes and the chemical reactions that determine the oxidation kinetic law are comparable [6]. The temperature at which the chemical interaction of metal with water vapor begins is as lower as the metal surface is more developed. The oxidation of aluminium proceeds at a high speed at low partial pressure of oxygen-containing gases, depending on the temperature. In the initial stage of aluminium oxidation, an amorphous layer, barrier type is formed, followed by diffusion of metal cations and oxygen anions through the oxide layer [7]. This is an endothermic process.

The aluminium oxidation is carried out at humidity up to $4 \%$. Water molecules are adsorbed on the surface. After adsorption with a weak Van der Waals interaction, chemisorption begins:

$$
2 \mathrm{Al}+3 \mathrm{H}_{2} \mathrm{O} \rightarrow 6 \mathrm{H}+\mathrm{Al}_{2} \mathrm{O}_{3} .
$$

Free atomic hydrogen propagates in the layer and ionizes. Oxygen decomposes into atoms to form the metastable phase $\mathrm{Al}_{2} \mathrm{O}_{3}$ and hydrogen 
monohydroxide $\mathrm{AlOOH}$, which is converted to the trihydroxide $\mathrm{Al}(\mathrm{OH})_{3}$. At $18-20{ }^{\circ} \mathrm{C}$ in air, aluminium forms a thin, protective, oxidized layer of:

$$
\mathrm{Al}_{2} \mathrm{O}_{3} \rightarrow \mathrm{AlOOH} \rightarrow \mathrm{Al}(\mathrm{OH})_{3} .
$$

An increase in the oxide layer is possible with increasing temperature, by diffusion of cations through the layer to the gas-oxide surface and vice versa, diffusion of anions through the layer to the interface of the oxide layer-metal [8].

An increase in the oxide layer wegth is possible with increasing temperature, and the transition of the metal from solid to liquid does not change things. The oxidation kinetics determine the cationic diffusion. The oxygen partial pressure has no effect. The oxidation of metals is also called dry corrosion.

Nano-microcrystalline alloys differ from massive specimens. When obtaining products from them, it is necessary to apply elevated temperatures, which requires studying the mechanism of interaction with air during the hot extrusion process. We consider PFC as a method for rapid solidification by melt [9]. As a result of the fast crystallization, blanks with highly fine structures are obtained in the form of metal ribbons.

The blanks are compacted by processes of plastic deformation at elevated temperatures such as hot extrusion (above $450-500{ }^{\circ} \mathrm{C}$ ). The heating structure is shown in $[9,10]$.

The tribological properties and the wear characteristics of aluminum alloys are studied in papers [11-14].

\section{THEORETICAL BASIS}

The oxide layer prevents contact in the consolidation of microcrystalline powders and strips. This shows that it is necessary to know the process of interaction of the rapidly hardened blanks with the gas phase at high temperatures close to those required for hot extrusion.

Oxidation processes are the subject of both kinetic studies and the thermodynamic capabilities of alloys to form oxide layers.

The different kinetic dependences of oxidation of metals and their corresponding dependences of the oxidation rate on time, according to [15], are shown schematically in Fig. 1.

The three oxidation models can occur in the same metal, depending on the production conditions and operation.

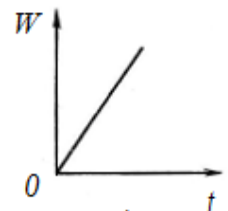

a)

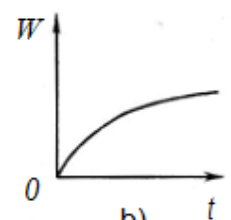

b)

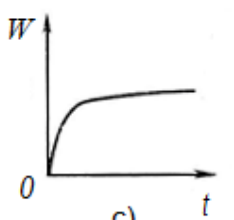

c)
Fig.1. Schematic dependence of the specific weight $W$ of the oxide layer on time $t$ [15]; a) Linear dependence; b)

Parabolic dependence; c) Logarithmic dependence

Nikitin's formal kinetics is used to study the kinetics of ribbons and bulk samples of Al-Si alloys. According to [15], kinetic data for aluminium alloys are shown as a function of:

$$
W^{n}=\mathrm{k}_{\mathrm{j}}\left(t_{i}+t_{0}\right)+\text { const },
$$

$n$ is an exponent, $t_{i}$ is oxidation time, the time $t_{0}$ in [s] is an incubation period that is short. The parameter to (Equation 3) is zero if the weight measurement starts with heating. The degree of function depends on the type of alloy and the temperature of the investigation.

There is also a fourth dependence, which follows cubic law or cubic relation:

$$
W^{3}=\mathrm{k} t+\text { const }
$$

Some metals under specific conditions follow this cubic law. Zirconium is oxidized by this law. The oxidation of metal initially follows the parabolic law, and the oxide is protective. But the layer breaks after acquiring a critical thickness and there are direct access to oxygen of the metal surface by grow parabolically again.

\section{EXPERIMENTAL PROCEDURE}

Samples with various alloying elements in the form of ribbons and extrusion samples were obtained by the PFC method (Fig. 2a, Table 1). The thickness of ribbons are about $70-80 \mu \mathrm{m}$ at average cooling rate of approximately $10^{5} \mathrm{~K} \cdot \mathrm{s}^{-1}$.

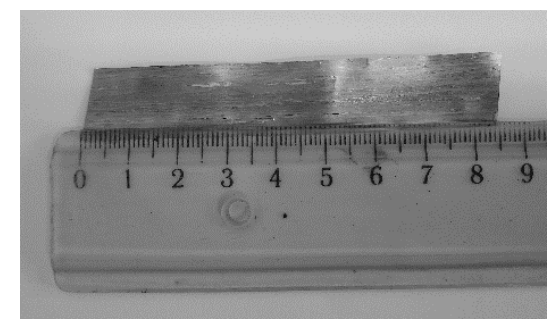

a)

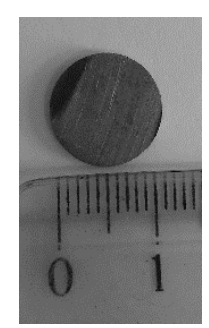

b)
Fig.2. Samples: a) Ribbon R2; b) Extruded E1

The extruded bars are $12 \mathrm{~mm}$ in diameter (Fig. 2b). 
Comparing the results of oxidation of various samples, we can make conclusions about the effect of the composition of nano-microcrystalline ribbons on the oxidation process and compare the oxidation of ribbons and extrusion samples.

The increase in the specific weight $W$ of the specimens during the experiment is monitored using Setaram thermogravimetric method with relative sensibility $4 \cdot 10^{-8} \mathrm{~g}$ and stability $1.10^{-6} \mathrm{~g}$.

Table 1. Chemical composition in wt. \% of the analyzed samples

\begin{tabular}{|l|c|}
\hline \multicolumn{1}{|c|}{ Sample } & $T\left[{ }^{\circ} \mathrm{C}\right]$ \\
\hline Base ribbon R1 Al-0.2Fe-11.5Si & 550 \\
\hline Ribbon R2 Al-7Si & 490 \\
\hline Ribbon R3 Al-12Si & 490 \\
\hline Ribbon R4 Al-10Fe-2V-10Si & 550 \\
\hline Massive alloy M Al-10Fe-2V-10Si & 500 \\
\hline Casting alloy C Al-12Si & 512 \\
\hline Extrusion sample E1 Al-10Fe-2V-10Si & 550 \\
\hline Extrusion sample E2 Al-12Si & 500 \\
\hline
\end{tabular}

The temperature was maintained within $\pm 0.5^{\circ} \mathrm{C}$. The duration was $120 \mathrm{~min}$.

We determine $n$ :

$$
n=\frac{\alpha \ln t}{\ln W} .
$$

We draw the line $\ln W(\ln t)$. Then $n$ is obtained as 1 on the slope of the line $\ln W(\ln t)$.

Fig. 3 shows the processed data for Al-12Si alloy.

The parabola (Fig. 3a) after logarithm becomes a line with a slope (Fig. 3b).

The exponent $n$ of all samples are calculated by the same procedure. Fig. 4 shows the lines for ribbons R2 (Fig. 4a) and R3 (Fig. 4b).

All curves suggest the same oxidation mechanism due to the predominant aluminium component. This means that we can determine $n$ for aluminium alloys of $\mathrm{Al}-1 \mathrm{Mg}-0.5 \mathrm{Si}$ [16].

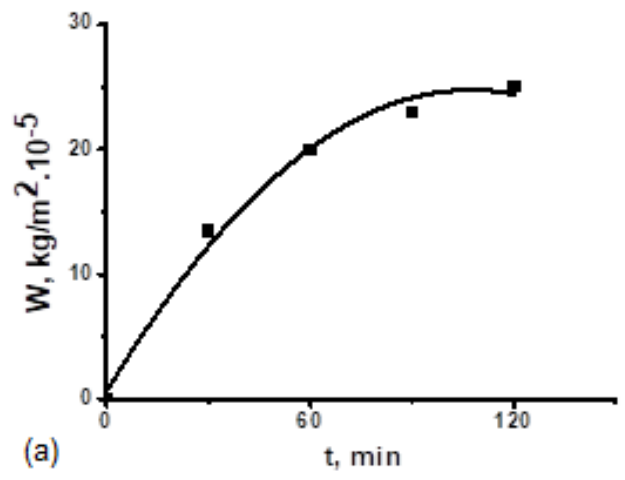

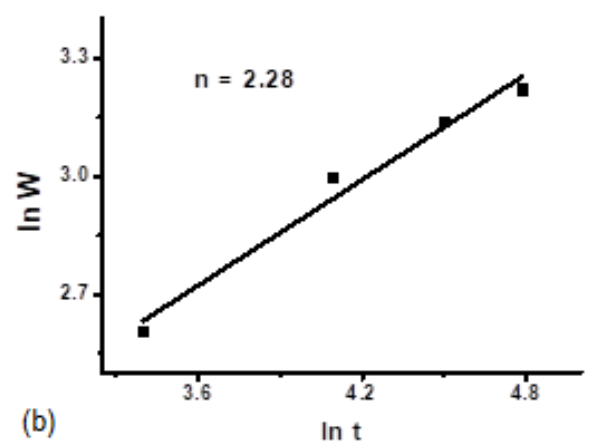

Fig.3. Casting alloy $\mathrm{Al}-12 \mathrm{Si}(\mathrm{Al}-12 \mathrm{Si})$ at isothermal heating $120 \mathrm{~min}$ : a) Isotherm $W(t)$; b) Linear dependence $\ln W(\ln t)$

The results for the calculation of the exponent $n$ for all aluminium alloys are shown in Table 2 .
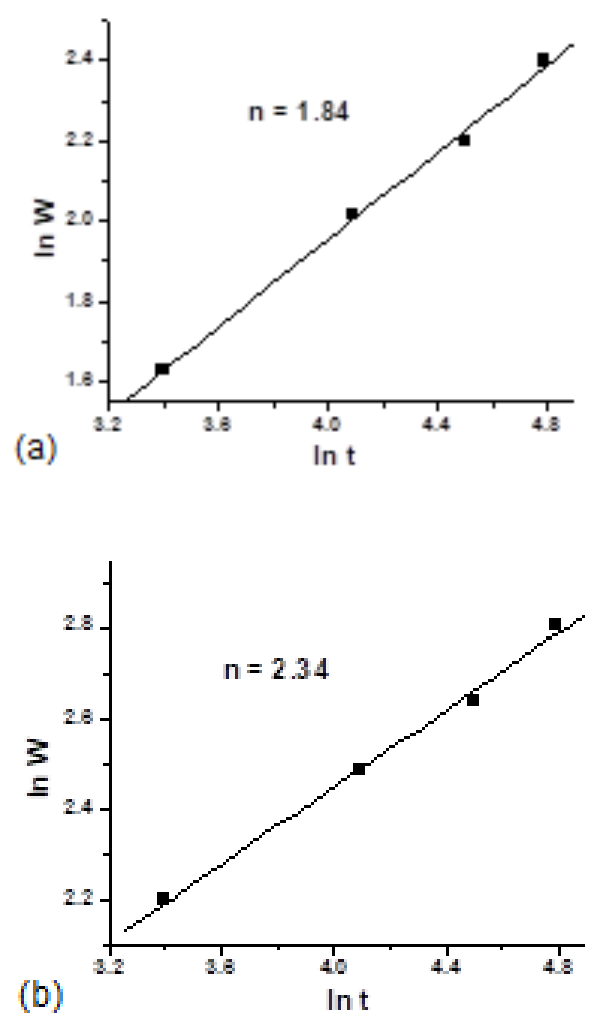

Fig.4. Linear dependence $\ln W(\ln t)$ and exponent $n$ for: a) Ribbon R2; b) Ribbon R3

Exponent $n=2$ describes the formation of a dense oxide layer, which is composed only of $\mathrm{Al}_{2} \mathrm{O}_{3}$, since $\mathrm{Fe}, \mathrm{V}$ and $\mathrm{Si}$ are connected in the intermetallic phase $\mathrm{Al}_{12}(\mathrm{Fe}, \mathrm{V})_{3} \mathrm{Si}$ and do not participate in the formation of the oxide layer for AL-Fe-V-Si alloys. Si also does not participate in the oxide layer for the Al-12Si casting alloy. It can be expected that the extrudates will have a higher degree of oxidation due to larger particles and, accordingly, a coarser structure or a larger oxide surface. 
Table 2. The calculated value of the exponent $n$ for the different samples

\begin{tabular}{|l|c|}
\hline \multicolumn{1}{|c|}{ Sample } & $n$ \\
\hline Base ribbon R1 Al-0.2Fe-11.5Si & 2.02 \\
\hline Ribbon R2 Al-7Si & 1.84 \\
\hline Ribbon R3 Al-12Si & 2.34 \\
\hline Ribbon R4 Al-10Fe-2V-10Si & 1.61 \\
\hline Massive alloy M Al-10Fe-2V-10Si & 1.62 \\
\hline Casting alloy C Al-12Si & 2.28 \\
\hline Extrusion sample E1 Al-10Fe-2V-10Si & 1.52 \\
\hline Extrusion sample E2 Al-12Si & 2.55 \\
\hline
\end{tabular}

The mechanism and kinetics of oxidation depend on the alloying elements.

Magnesium, copper, silicon are the main alloying elements. Chromium, nickel, titanium, etc. are used as additives. as for aluminium alloys do not exceed $10 \%$. Water vapor adsorbed from the surface of the layer is retained even after the metal is heat treated to $350{ }^{\circ} \mathrm{C}$. The residue is aluminium hydrate in the oxide layer can be removed at higher temperatures or can react with the metal to form hydrogen.

Under normal conditions, this layer does not interact with water even when boiling and has high mechanical strength. When the protective oxide layer is removed, aluminium reacts with water vapor from the air, converting it to aluminium hydroxide and hydrogen, releasing heat [16].

The presence of magnesium in aluminium alloys leads to the formation of pores in the oxide layer [17].

\section{RESULTS AND DISCUSSION}

The oxidation kinetics of Al-Si alloys is parabolic and is described by the equation (3), where the exponent index $1<n<2, n=2$ or $n>2$.

Many authors assume that the oxidation of aluminium alloys is performed by exponent 1 . The calculated values $n=2$ for samples presented indicate a dense oxide coating. In our study, several samples have this value - Base ribbon R1 Al-0.2Fe-11.5Si, Ribbon R2 Al-7Si, Ribbon R3 Al12Si. In our previous study, the highest oxidation tendency has ribbon with $\mathrm{Mg}$ additive [9].

At isothermal heating $550{ }^{\circ} \mathrm{C}$ for $120 \mathrm{~min}$. the specific weight of the oxide layer $W$ increases in different ways for different types of samples. The measured values are shown in Table 3.
Table 3. The specific weight $W$ of the oxide layer on time $(120 \mathrm{~min})$ for the samples

\begin{tabular}{|l|c|}
\hline \multicolumn{1}{|c|}{ Sample } & $W\left[\mathrm{~kg} / \mathrm{m}^{2} \cdot 10^{-5}\right]$ \\
\hline Ribbon R3 Al-12Si & 4.0 \\
\hline Extrusion sample E2 Al-12Si & 22.5 \\
\hline Casting alloys C Al-12Si & 24.0 \\
\hline Ribbon R4 Al-10Fe-2V-10Si & 5.0 \\
\hline $\begin{array}{l}\text { Extrusion sample E1 } \\
\text { Al-10Fe-2V-10Si }\end{array}$ & 25.0 \\
\hline
\end{tabular}

The extruded samples oxidize faster than the corresponding samples in the form of ribbons due to their rough structure.

However, in this case, the extruded samples have a smaller exponent and, accordingly, oxidize more slowly because the fine structure obtained by PFC method.

As can be seen from Fig. 3a the oxide coating on the samples increases parabolically over time. The aluminium layer thus formed has protective properties to prevent further interaction. Aluminium oxide has a high melting point. It also does not dissolve in solid or liquid metal. The oxide layer has high mechanical strength.

An important feature of the nanomicrocrystalline alloys based on Al-Si alloys studied by us is their tendency to oxidation at high temperatures. During the surface oxidation, an oxide layer is formed, the properties of which depend on the temperature and the composition of the starting alloy.

The oxide layer protects the aluminium alloy from further destruction (Fig. 5).

Parameter $n=2$ is characteristic Al-Si alloys, without micro- and macro-impurities, where in such alloys the oxide layer is dense, Fig. 5.

As is known, alloys with a complex composition (high iron) also have a complex behavior with increasing temperatures $[18,19]$.

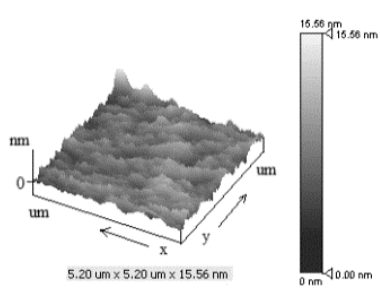

a)

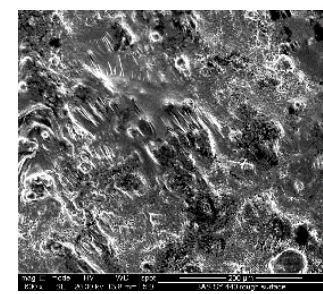

b)
Fig.5. Surface of ribbon 2: a) NanoScan image of wheel site; b) SEM of air site

In addition to the increase of the oxide layer in these alloys, a two-stage decomposition of the saturated aluminium solution obtained by rapid crystallization is observed [20]. 


\section{CONCLUSIONS}

The results of weight gain-time studies at (490550) ${ }^{\circ} \mathrm{C}$ fit the parabolic low for nanomicrocrystalline Al-Si alloys show decreased oxidation tendency with thin and strong oxide skin with $n$ exactly equal to 2 . This is a prerequisite for the preparation of massive samples from these alloys of good density in subsequent treatment.

Rapid solidification is an effective technology in combining microstructure and mechanical properties.

The aluminium alloys are very important for the industry while the silicon is traditionally used as alloying element. Dotting $\mathrm{Al}-\mathrm{Si}$ alloys with some third constituent might change some their properties, especially the oxidation resistance. The oxide layer formed during rapid solidification protects the alloy from the air. It prevents better contact between the ribbons during hot extrusion, but degrades the mechanical properties of the resulting solid blanks.

The kinetics of growth of the oxide layer on samples of aluminium ribbons and extrudates with different composition were studied. Knowledge of the oxidation process allows to take measures to minimize the harmful effects of the oxide layer on the structure and properties of the samples. Formal kinetics makes it possible with comparatively available means to predict the properties of samples obtained by hot extrusion from rapid solidified aluminium alloys.

The concentration of Si plays an important role in the stage of formation of the structure such as the formation of a new silicon phase, leading to the consolidation of the structure. The addition of Fe improves the stability of the ribbons. Fe becomes useful additive as alloys show decreased oxidation tendency by rapid solidification method. This results in dense solid samples ensures resistance to high-temperature gas corrosion. The exponent $\mathrm{n}$ is exact equal to 2 .

The quality of the ribbons depends on the cooling rate of the melt or the speed of rotation of the disk. Increasing this speed not only changes the appearance of the ribbons, but also their tendency to oxidize. Increasing the velocity improves the resistance of the tapes to oxidation. Acceleration of cooling indicates that the protective properties of the oxide layer approach those of pure Al-Si alloys without additives.

The oxidation of metals by heating brings great losses to the industry due to the fact, that the corrosion resistance of aluminium alloys is extremely low. Products intended for operation at high temperatures are made of special heatresistant alloys or, if possible, coatings are applied, which increase the resistance to the action of gas corrosion. Increasing the heat resistance of the metal is achieved by saturating its surface layer with aluminium (aluminization), silicon (siliconizing), chromium (thermochrome). The processes of saturation with aluminium-silicon and chromium-silicon alloys are also practiced.

\section{NOTE}

The abstract of this paper is published at the $10^{\text {th }}$ International Conference on Tribology BALKANTRIB '20 organised in Belgrade, on May 2022, 2021.

\section{REFERENCES}

[1]. V.V. Rao, Rapid solidification processing of some aluminium alloys. NML Technical Journal, 38 (4), 1996: 133-150.

[2]. T. Dursun, C. Soutis, Recent developments in advanced aircraft aluminium alloys. Materials \& Design (1980-2015), 56, 2014: 862-871. https://doi.org/10.1016/j.matdes.2013.12.00 $\underline{2}$

[3]. A. Heinz, A. Haszler, C. Keidel, S. Moldenhauer, R. Benedictus, W.S. Miller, Recent development in aluminium alloys for aerospace applications. Materials Science and Engineering: A, 280 (1), 2000: 102-107.

https://doi.org/10.1016/S09215093(99)00674-7

[4]. B. Stojanovic, J. Glisovic, Automotive Engine Materials, in: S. Hashmi (Ed.), Reference Module in Materials Science and Materials Engineering. Elsevier, Oxford, 2016, pp.1-9.

[5]. A. Vencl, Tribology of the Al-Si Alloy Based MMCs and Their Application in Automotive Industry, in: L. Magagnin (Ed.), Engineered Metal Matrix Composites: Forming Methods, Material Properties and Industrial Applications. Nova Science Publishers, New York, 2012, pp.127-166.

[6]. V.I. Dobatkin, P.M. Gabidullin, B.A. Kolachev, G.S. Makarov, Gases and oxides in aluminum deformable alloys. Metallurgiya, Moscow, 1976 [in Russian].

[7]. P.E. Blackburn, E.A. Gulbransen, Aluminum reaction with water vapor, dry oxygen, moist oxygen and moist hydrogen between $500^{\circ}$ and $625^{\circ} \mathrm{C}$. Jornal of The Electrochemical Society, 107, 1960: 944-950.

https://doi.org/10.1149/1.2427576 
[8]. C. Wagner, The distribution of cations in metal oxide and metal sulphide solid solutions formed during the oxidation of alloys. Corrosion Science, 9, 1969: 91-109.

https://doi.org/10.1016/S0010938X(69)80046-6

[9]. B. Barbov, A. Petrova, Oxidation of Aluminum Alloys in the Processing Condition, $14^{\text {th }}$ International Scientific Conference Space, Ecology, Safety (SES 2018), 7-9 November 2018, Sofia, Bulgaria, 447-450.

[10].B. Barbov, A. Petrova, Microstructure and Mechanical Properties of NanoMicrocrystalline Aluminum Alloys, $14^{\text {th }}$ International Scientific Conference Space, Ecology, Safety (SES 2018), 7-9 November 2018, Sofia, Bulgaria, pp. 451-456.

[11].A. Vencl, I. Bobić, M. Stanković, P. Hvizdoš, B. Bobić, B. Stojanović, F. Franek, Influence of Secondary Phases in A356 MMCs on Their Mechanical Properties at Macro- and Nanoscale. Journal of the Brazilian Society of Mechanical Sciences and Engineering, 42 (3), 2020: 115.

https://doi.org/10.1007/s40430-020-2197-6

[12].M. Kostecki, J. Woźniak, T. Cygan, M. Petrus, A. Olszyna, Tribological properties of aluminium alloy composites reinforced with multi-layer graphene - the influence of spark plasma texturing process. Materials, 10 (8), 928, 2017: 1-14.

https://doi.org/10.3390/ma10080928

[13].M. Kandeva, I. Panov, B. Dochev, Abrasive wear of a hypereutectic alloy ALSI18, modified by different modifiers. Journal of the Balkan Tribological Association, 26 (4), 2020: 661-673.
[14].M. Kandeva, Iv. Panov, B. Dochev, Effects of nanomodifiers on the wear resistance of aluminum-silicon alloy ALSI18 in tribosystems in case of reversive friction and lubrication. Journal of the Balkan Tribological Association, 26 (4), 2020: 637-652.

[15].V.I. Nikitin,Calculation of heat resistance of metals. Metallurgiya, Moscow, 1976. [in Russian].

[16].W. Kahl and E. Fromm, Examination of the strength of oxide skins on aluminum alloy melts. Metallurgical transactions $B, 16,1985$ : 47-51.

https://doi.org/10.1007/BF02657487

[17].S. Yaneva, L. Stojanova, T. Markov, Oxidation of solid aluminium silicon alloys in air. Cryst. Res. Technol., 22, 1987: 251-258. https://doi.org/10.1002/crat.2170220219

[18].E.J. Lavernia, J.D. Ayers, T.S. Srivatsan, Rapid solidification processing with specific application to aluminium alloys. Int. Mater., 37 (1), 1992: 1-44.

https://doi.org/10.1179/imr.1992.37.1.1

[19].P. Gilman, M. Zedalis, J. Peltier, S. Das, Rapidly solidified aluminum-transition metal alloys for aerospace applications. AIAA-88-444. Aircraft Desigh, Systems and Operations Conf. Atlanta. 7-9 September, 1988. https://doi.org/10.2514/6.1988-4444

[20].S. Yaneva, A. Kalkanli, K. Petrov, R. Petrov, Ir. Yvan Houbert, S. Kassabov, Structure development in rapidly solidified Al-Fe-V-Si ribbons. Materials Science and Engineering, A 373, 2004: 90-98.

https://doi.org/10.1016/j.msea.2003.12.034 